\title{
Methanol-driven enhanced biological phosphorus removal with a syntrophic consortium
}

\section{Running title: Methanol-driven EBPR}

Carlota Tayà, Javier Guerrero, Gianni Vanneste, Albert Guisasola and Juan A. Baeza*

*Corresponding author:

Juan Antonio Baeza

Departament d'Enginyeria Química. Escola d'Enginyeria.

Universitat Autònoma de Barcelona, 08193, Bellaterra (Barcelona).Spain.

Tel: 34935811587

Fax: 34935812013

email: juanantonio.baeza@uab.cat

Carlota Tayà

Departament d'Enginyeria Química. Escola d'Enginyeria.

Universitat Autònoma de Barcelona, 08193, Bellaterra (Barcelona).Spain.

Tel: 34935814795

email: carlota.taya@uab.cat

Javier Guerrero

Departament d'Enginyeria Química. Escola d'Enginyeria.

Universitat Autònoma de Barcelona, 08193, Bellaterra (Barcelona).Spain.

Tel: 34935814798

email: franciscojavier.guerrero@uab.cat

Gianni Vanneste

Departament d'Enginyeria Química. Escola d'Enginyeria.

Universitat Autònoma de Barcelona, 08193, Bellaterra (Barcelona).Spain.

Albert Guisasola

Departament d'Enginyeria Química. Escola d'Enginyeria.

Universitat Autònoma de Barcelona, 08193, Bellaterra (Barcelona).Spain.

Tel: 34935811879

email: albert.guisasola@uab.cat 


\begin{abstract}
The presence of suitable carbon sources for enhanced biological phosphorus removal (EBPR) plays a key role in phosphorus removal from wastewater in urban WWTP. For wastewaters with low VFAs content, an external carbon addition is necessary. As methanol is the most commonly external carbon source used for denitrification it could be a priori a promising alternative, but previous attempts to use it for EBPR have failed. This study is the first successful report of methanol utilization as external carbon source for EBPR. Since a direct replacement strategy (i.e. supply of methanol as a sole carbon source to a propionic-fed PAOenriched sludge) failed, a novel process was designed and implemented successfully: development of a consortium with anaerobic biomass and PAOs. Methanol-degrading acetogens were i) selected against other anaerobic methanol degraders from an anaerobic sludge, ii) subjected to conventional EBPR conditions (anaerobic + aerobic) and iii) bioaugmented with PAOs. EBPR with methanol as a sole carbon source was sustained in a mid-term basis with this procedure.
\end{abstract}

\title{
KEYWORDS
}

Enhanced biological phosphorus removal (EBPR), methanol, acetogens, polyphosphate accumulating organisms (PAOs), glycogen accumulating organisms (GAOs) 


\section{INTRODUCTION}

Enhanced biological phosphorus removal (EBPR) is the most sustainable technology to remove phosphorus from wastewater since it does not need any chemical addition. EBPR is based on the enrichment of activated sludge with polyphosphate accumulating organisms (PAOs). PAOs can take up carbon sources under anaerobic conditions and store them as poly$\beta$-hydroxyalkanoates (PHA). This storage requires energy provided by the hydrolysis of polyphosphate (Poly-P) and reduction power obtained from glycogen utilization. The release of phosphate produced under anaerobic conditions is compensated by its aerobic uptake, leading to net P-removal. Volatile fatty acids (VFAs) as acetic and propionic are the most suitable and commonly studied carbon sources for EBPR (Pijuan et al., 2004; Zeng et al., 2003), but other compounds such as glucose (Jeon and Park, 2000), ethanol (Puig et al., 2008), butyrate, lactate, or valerate have also been used (Oehmen et al., 2007). Glycerol is another promising carbon source that has been recently demonstrated as capable to maintain PAOs activity (Guerrero et al., 2012), although extended anaerobic conditions were required for glycerol fermentation to VFAs. Given the limited range of carbon sources valid for PAOs, the presence of VFAs in the influent wastewater plays a key role for EBPR success in urban WWTP. For wastewaters with low VFAs content, the utilization of sludge prefermentation to produce these compounds (Tong and Chen, 2010) or external carbon addition may be necessary. The latter is usually not economically feasible and it increases the overall plant carbon footprint (Isaacs and Henze, 1995; Yuan et al., 2010). Moreover, when choosing a possible external organic matter, both the economics and the selective use of the carbon source by PAOs against glycogen accumulating organisms (GAOs, the PAOs competitors) has to be considered (Puig et al., 2008). 
Denitrification is another biological process that may require external carbon addition and hence, it would be very practical to find a carbon source suitable for both processes. Methanol is the most commonly used external carbon source for denitrification (e.g. Purtschert et al., 1996) and, as such, its utilization to make EBPR possible seems a priori a promising alternative. Moreover, the current research on methanol production from non-fossil sources (i.e. bio-methanol) may upgrade the process sustainability. However, so far, it has been shown that methanol is inappropriate for biological phosphorus removal. Randall et al., (1997) showed that methanol could not be used as carbon source in a SBR cultivated with glucose fermentation products. Cho and Molof (2004) investigated the use of a combined carbon source (methanol and acetic acid) for simultaneous nitrogen and phosphorus removal. They found the highest $\mathrm{P}$ removal when all the influent COD was acetic acid, indicating that methanol was not used for P removal purposes. Similarly, Louziero et al. (2002) studied the effect of methanol on the simultaneous biological removal of $\mathrm{N}$ and $\mathrm{P}$ and concluded that despite methanol was probably not utilized by PAOs, methanol addition was critical, since it depleted the available nitrate and thus allowed EBPR to take place. Puig et al. (2008) studied methanol utilization in an ethanol-acclimated EBPR sludge and observed that methanol was not a suitable carbon source in short-term tests. Given this limited research, further investigation is required to assess whether methanol could be used by PAOs during long-term EBPR operation.

Hence, the purpose of this study was to investigate the possibility of using methanol as external carbon source for EBPR as an alternative for conventional VFAs (i.e. acetate and propionate). Two different approaches were conducted. On the one hand, methanol was supplied as sole carbon source to a PAO-enriched sludge which was fed with propionic acid during 30 days. This was a successful acclimation approach similar to that conducted in a previous study with glycerol as sole carbon source (Guerrero et al., 2012), but never applied 
before to achieve methanol-driven EBPR. On the other hand, and given the fact that this direct replacement approach was likely to fail, the utilization of a syntrophic consortium was also planned. The initial idea was to develop a consortium with conventional anaerobic biomass and PAOs. Then, the anaerobic fraction (essentially, acetogens) would degrade methanol, while PAOs would live off the degradation byproducts enabling EBPR. For this aim, a first step was necessary where an anaerobic sludge was enriched in methanoldegrading acetogens selected against other methanol degraders (essentially methanogens). Methanogens were absolutely undesired in this consortium since they could either use methanol or acetate for methanogenesis becoming then competitors to PAOs and acetogens. This selection was conducted according to the guidelines presented in the works of Florencio et al. (1993a, b and 1995).

\section{MATERIALS AND METHODS}

\section{$\underline{2.1 \text { Equipment }}$}

Three different sequencing batch reactors (SBR) were used. Prior to this study, SBR-A and SBR-B (10 L each) were used for obtaining and maintaining a PAO-enriched sludge with propionic acid as sole carbon source. The activated sludge, obtained from a municipal WWTP (Granollers, Spain), was enriched in PAOs using propionic acid to avoid Competibacter GAOs growth (Pijuan et al. 2004) and thus, to obtain a highly PAO-enriched sludge. Moreover, propionic-fed PAOs can easily switch to consume other carbon sources as acetic acid without any acclimation period (Pijuan et al., 2009). Then in this study, SBR-A was used to test the feasibility of a direct replacement of propionic acid for methanol, while SBR-B was used as source of PAO-enriched sludge for a bioaugmentation strategy. Both SBRs were fully monitored for oxygen (Hamilton Oxyferm 120 probe), pH (Hamilton polilyte Pro120 probe), ORP and temperature. A PLC (SIMATIC S7-226, Siemens) controlled the equipment and 
phase configuration. The SBRs were operated with 4 cycles per day with a controlled temperature of $25 \pm 1^{\circ} \mathrm{C}$. $\mathrm{HCl}(1 \mathrm{M})$ and $\mathrm{NaOH}(1 \mathrm{M})$ were added to control the $\mathrm{pH}$ at $7.50 \pm$ 0.05. Acid and base were pumped using precise peristaltic dosage pumps (Watson Marlow 400 FS/M1 OEM). Each cycle consisted of $2 \mathrm{~h}$ anaerobic phase, $3.5 \mathrm{~h}$ aerobic phase, $25 \mathrm{~min}$ of settling and 5 min to extract $5 \mathrm{~L}$ of the supernatant. A fixed nitrogen gas flow was sparged during anaerobic phase to maintain strict anaerobic conditions. Dissolved oxygen (DO) was maintained from 3.5 to $4.5 \mathrm{mg} \cdot \mathrm{L}^{-1}$ in the aerobic phase to avoid oxygen limitations. A volume of $5 \mathrm{~L}$ (synthetic wastewater + concentrated carbon solution) was added during the first 5 minutes of the cycle, resulting in a HRT of $12 \mathrm{~h}$. The synthetic wastewater solution $(4.97 \mathrm{~L})$ consisted of (mg. $\mathrm{L}^{-1}$ in reverse osmosis water): $110.5 \mathrm{KH}_{2} \mathrm{PO}_{4}, 83.7 \mathrm{~K}_{2} \mathrm{HPO}_{4}, 100 \mathrm{NH}_{4} \mathrm{Cl}$, 43.9 $\mathrm{MgSO}_{4} \cdot 7 \mathrm{H}_{2} \mathrm{O}, 160 \mathrm{MgCl}_{2} \cdot 6 \mathrm{H}_{2} \mathrm{O}, 42 \mathrm{CaCl}_{2} \cdot 2 \mathrm{H}_{2} \mathrm{O}, 50$ allylthiourea (ATU) to inhibit nitrification and $30 \mathrm{~mL}$ of nutrient solution. The initial phosphorus concentration was $20 \mathrm{mg}$ $\mathrm{P}-\mathrm{PO}_{4}{ }^{3-} \cdot \mathrm{L}^{-1}$. The nutrient solution $\left(\mathrm{g} \cdot \mathrm{L}^{-1}\right)$ consisted of: $1.5 \mathrm{~g} \mathrm{FeCl} \cdot 6 \mathrm{H}_{2} \mathrm{O}, 0.15 \mathrm{~g} \mathrm{H}_{3} \mathrm{BO}_{3}, 0.03 \mathrm{~g}$ $\mathrm{CuSO}_{4} \cdot 5 \mathrm{H}_{2} \mathrm{O}, 0.18 \mathrm{~g} \mathrm{KI}, 0.12 \mathrm{~g} \mathrm{MnCl}_{2} \cdot 4 \mathrm{H}_{2} \mathrm{O}, 0.06 \mathrm{~g} \mathrm{Na}_{2} \mathrm{MoO}_{4} \cdot 4 \mathrm{H}_{2} \mathrm{O}, 0.12 \mathrm{~g} \mathrm{ZnSO}_{4} \cdot 7 \mathrm{H}_{2} \mathrm{O}$, $0.15 \mathrm{~g} \mathrm{CoCl}_{2} \cdot 6 \mathrm{H}_{2} \mathrm{O}$ and $68.5 \mathrm{~mL}$ EDTA $0.5 \mathrm{M} .0 .03 \mathrm{~L}$ of carbon source solution (either propionic acid or methanol) was added from a separate concentrated solution to obtain the desired initial concentration in the reactor. The sludge residence time (SRT) was maintained at 20 days by periodic wastage at the end of the aerobic phase in SBR-B during all the operational period and in SBR-A when operating with propionic acid. SBR-A was not purged during the methanol-fed period to avoid biomass washout and consequently, SRT increased during this period.

On the other hand, SBR-C was used to grow the syntrophic consortium for simultaneous methanol and phosphorus removal. SBR-C $(13 \mathrm{~L})$ had only minor differences with respect to SBR-A or SBR-B. Initial anaerobic sludge inoculum was obtained from the anaerobic digester of a municipal WWTP (Granollers, Spain). During the anaerobic phase, no nitrogen 
was sparged to avoid possible methanol losses due to evaporation. When aerobic conditions were required, DO was maintained from 1.5 to $2.0 \mathrm{mg} \cdot \mathrm{L}^{-1}$ with an on/off controller. $\mathrm{pH}$ was also controlled at $7.5 \pm 0.1$ using $\mathrm{HCl}(1 \mathrm{M})$ and bicarbonate $(1 \mathrm{M})$. Bicarbonate was used as $\mathrm{pH}$-increaser instead of $\mathrm{NaOH}$ because it is a required co-substrate in the acetogenic breakdown of methanol (Florencio et al., 1993a). A volume of $4 \mathrm{~L}$ of synthetic wastewater was added during the first 5 min of each cycle. A settling phase took place at the end of each cycle, followed by 10 min to extract $4 \mathrm{~L}$ of the supernatant. SBR-C was operated under different configurations during this work, which are summarized in Table I. The synthetic media was similar to the media described above with the only difference of cobalt addition $\left(0.2 \mathrm{mg} \cdot \mathrm{L}^{-1} \mathrm{CoCl}_{2} \cdot 6 \mathrm{H}_{2} \mathrm{O}\right)$ to avoid its limitation for acetogenic bacteria (Florencio et al., 1993a). SRT in this reactor was kept at $20 \mathrm{~d}$.

\section{$\underline{2.2 \text { Batch experiments }}$}

Off-line batch experiments were performed in a magnetically stirred vessel (2 L). Each batch experiment mimicked a SBR-B cycle with a first anaerobic phase (by nitrogen sparging) and a subsequent aerobic phase (by air sparging). The pH (WTW Sentix 81) and DO (WTW CellOx 325) probes were connected to its multiparametric terminal which was in turn connected via RS232 to a PC allowing for data monitoring and storage. The software also manipulated a high precision microdispenser (Crison Multiburette 2S) for $\mathrm{pH}$ control with acid/base addition. Biomass (2 L) was withdrawn at the end of the aerobic phase of the SBR-A and was placed in the stirred vessel under anaerobic conditions. The experiment started with a pulse of concentrated feed with the desired propionic acid and P concentration.

Formaldehyde as a possible carbon source for PAOs was tested in a batch experiment by mimicking a typical EBPR cycle with $2 \mathrm{~h}$-anaerobic and $3 \mathrm{~h}$-aerobic phases. A pulse of 100 $\mathrm{mg} \cdot \mathrm{L}^{-1}$ of formaldehyde was introduced at the beginning of the experiment and $\mathrm{P}$ and formaldehyde concentrations were monitored. 
Finally, some batch experiments were performed with anaerobic sludge in a 1L vessel where a pulse of $600 \mathrm{mg} \cdot \mathrm{L}^{-1}$ of methanol was added and the acetic acid production and methanol degradation were monitored.

$\underline{2.3 \text { Sample preparation, chemical analyses and microbiological quantification. }}$

Representative samples of the mixed liquor were collected periodically for monitoring the SBRs cycles and the batch experiments. Solids quantification was performed with samples obtained at the end of the anaerobic and aerobic phases. Chemical analyses were performed in $0.22 \mu \mathrm{m}$ filtered samples (Millipore Millex-GP filters), while Millipore Glass fiber Prefilters were used for solids quantification.

Methanol concentration was determined by using an Agilent Technologies 7820 A GC equipped with a Innowax column $(30 \mathrm{~m} \times 0.53 \mathrm{~mm} \times 1.0 \mu \mathrm{m}$; length $\mathrm{x}$ internal diameter $\mathrm{x}$ film thickness) and a flame ionization detector (FID). A sample of $1 \mu \mathrm{l}$ was injected at a temperature of $50^{\circ} \mathrm{C}$ under pulsed split conditions (15psi). The carrier gas was helium with a split ratio of $20: 1$ at $1.2 \mathrm{psi}$, the column temperature was set at $45^{\circ} \mathrm{C}$ for the first 5 minutes, followed by an increase of $20^{\circ} \mathrm{C} \cdot \mathrm{min}^{-1}$ until the stable value of $110^{\circ} \mathrm{C}$ was reached. A cleaning step at $230^{\circ} \mathrm{C}$ during 5 min was used to remove any residue in the column. The run time was 20 min and the detector temperature was set at $300^{\circ} \mathrm{C}$. Phosphorus concentration (as mg P-PO ${ }_{4}^{3-} \cdot \mathrm{L}^{-1}$ ) in filtered samples was measured by a phosphate analyzer (Hach Lange 115 VAC Phosphax sc) based on the vanadomolybdate yellow method, where a two-beam photometer with LEDS measured the phosphate specific yellow color. Organic matter as COD, mixed liquor total suspended solids (TSS) and mixed liquor volatile suspended solids (VSS) were analyzed according to APHA (1995).

Fluorescence in situ hybridization (FISH) technique (Amann, 1995) coupled with confocal microscopy was used to quantify the biomass distribution. Hybridizations were performed with Cy3-labelled specific probes and Cy5-labelled EUBMIX for most bacteria (Daims et al., 
1999). PAOs were hybridized with PAOMIX probes and GAOs with GAOMIX, DF1MIX and DF2MIX probes as described in Guisasola et al. (2009). The distribution of PAOMIX, GAOMIX, DF1MIX and DF2MIX-labelled was quantified using image analysis as detailed in Jubany et al. (2009), where 40 randomly chosen CLSM fields from different $\mathrm{x}, \mathrm{y}$, and $\mathrm{z}$ coordinates were imaged (600× magnification) from each sample.

\section{RESULTS AND DISCUSSION}

\subsection{Direct replacement of propionic acid for methanol}

Methanol could not be used as an extra carbon source for EBPR purposes in previous studies. Therefore, our first approach was a direct replacement of the usual carbon source of SBR-A (200 $\mathrm{mg} \mathrm{COD} \cdot \mathrm{L}^{-1}$ of propionic acid) by methanol to avoid any alternative carbon source for PAOs. A low initial concentration of $50 \mathrm{mg} \cdot \mathrm{L}^{-1}$ of methanol was used to ensure its consumption only under anaerobic conditions, because methanol presence during the aerobic phase can affect the composition of the microbial community in a mid-term basis, as it can favor other aerobic methanol degraders. In this sense, minimizing the electron donor presence in the aerobic phase is a key factor to achieve a sludge highly enriched in PAOs. Given the low amount of COD added, SBR-A was not purged during this period to avoid biomass washout. Figure 1 summarizes the experimental results obtained during this period (30 days): the upper figures show the experimental phosphate (Left) and methanol (Right) profiles obtained in nine different cycles. Methanol consumption was negligible in the first day but anaerobic and aerobic methanol degradation was already observed on day 3 , indicating that the microbial community needed an adaptation period. Increased anaerobic methanol consumption was observed during the first 12 days of operation, although some methanol was still available under aerobic conditions. The initial concentration of methanol was decreased to $20 \mathrm{mg} \cdot \mathrm{L}^{-1}$ to ensure complete anaerobic methanol depletion. 
With respect to the experimental P profiles, anaerobic P-release was not observed despite the methanol consumption. However, some aerobic P-uptake was still maintained the first 5 days of operation. From day 8, neither anaerobic P-release nor aerobic P-uptake occurred, despite the existing anaerobic methanol consumption. This lack of EBPR activity proved that a propionate-fed PAO-enriched community was not able to grow on methanol as sole carbon source under the usual operating conditions of SBR-A. These results corroborated the reported data that stated that methanol could not be directly taken up by bio-P sludge (Randall et al., 1997; Louzeiro et al., 2002) even if the sludge was previously acclimated with another short chain alcohol as ethanol (Puig et al., 2008).

Figure 1 (Down) shows a gradual VSS decrease during this period, indicating that biomass was decaying as a consequence of the lack of a suitable carbon source. Over the 29 days of this experiment, the TSS and VSS decreased by $91 \%$ and $90 \%$, respectively. The VSS profile was fitted to equation 1 obtaining a decay coefficient of $b=0.074 \mathrm{~d}^{-1}\left(\mathrm{R}^{2}=0.95\right)$.

$$
\frac{\mathrm{dX}}{\mathrm{dt}}=-\mathrm{bX}
$$

The comparison of this decay rate with the values reported in the literature confirms that PAO biomass was virtually under starvation conditions due to the negligible utilization of methanol during this period. Lopez et al. (2006) studied the endogenous processes of PAOs during long-term (3-4 weeks) aerobic and anaerobic starvation. They obtained an aerobic decay value of $0.15 \mathrm{~d}^{-1}$ which is higher than the one obtained in our study, where starvation conditions alternate anaerobic and aerobic conditions. This observation agrees with the results observed in Lu et al. (2007), who studied the endogenous PAOs metabolism under intermittent aerobic-anaerobic conditions for a period of 8 days. They concluded that predominantly anaerobic conditions (15 min aeration every $6 \mathrm{~h})$ resulted in negligible cell decay rates and slower glycogen and poly-P utilization. Yilmaz et al. (2007) concluded that 
an alternating anaerobic and aerobic phase was more effective in maintaining biomass activity than aerobic conditions since PAOs were given suitable conditions to perform their normal anaerobic and aerobic metabolism.

The phosphorus content in the solids ( $\mathrm{g} P \cdot \mathrm{g}^{-1} \mathrm{TSS}$, Figure 1 Down) was approximated using equation 2, which assumes that the cell salts content is mainly poly-P $\left(\mathrm{Mg}_{0.33} \mathrm{~K}_{0.33} \mathrm{PO}_{3}\right.$, Brdjanovic et al., 1996; Marcelino et al., 2009). The constant value of 3.23 comes from dividing the poly-P molecular weight $\left(100 \mathrm{~g} \cdot \mathrm{mol}^{-1}\right)$ by the phosphorus molecular weight (31 $\left.\mathrm{g} \cdot \mathrm{mol}^{-1}\right)$. The P-cell content started at $0.04 \mathrm{~g} \mathrm{P} \cdot \mathrm{g}^{-1} \mathrm{TSS}$ and increased to $0.076 \mathrm{~g} \mathrm{P} \cdot \mathrm{g}^{-1} \mathrm{TSS} 8$ days after methanol introduction as sole carbon source. This increase is possibly due to the absence of an adequate carbon source and to the still active aerobic P-storage processes, as observed in the $\mathrm{P}$ profile (Figure $1 \mathrm{Left}$ ). When the maximum P-cell content was reached, it started to decrease rapidly because PAOs processes were no longer active, as observed in the flat profiles of P (Figure 1 Left). After 29 days, internal phosphorus content was almost depleted $\left(0.003 \mathrm{~g} \mathrm{P} \cdot \mathrm{g}^{-1} \mathrm{TSS}\right)$.

$$
\mathrm{P}-\text { cell content }=\frac{T S S-V S S}{T S S} \cdot \frac{1}{3.23}
$$

In order to gain more insight into the process, EBPR activity was monitored using batch tests with propionic acid as carbon source (Figure 2). After 12 days of methanol feeding, the Prelease rate was only $20 \%$ lower than the reference experiment (conducted before methanol feeding started). In contrast, aerobic P-uptake rate decreased $67 \%$ after 12 days of starvation. After 22 days of methanol-feed conditions, no P-uptake took place and only a small amount of $\mathrm{P}$ was released. At day 33, neither P-release nor P-uptake was observed, as a consequence of the important decrease in PAO biomass. Figure 2 shows that the aerobic P-uptake metabolism was more affected than the P-release, probably because the remaining active PAOs still had an important amount of stored Poly-P. 
These results confirm that the direct application of methanol to a PAO-enriched sludge was not a proper strategy to achieve simultaneous methanol and $\mathrm{P}$ removal. Nevertheless, this strategy was successfully applied in a previous work using glycerol as a sole carbon source (Guerrero et al., 2012). Whether direct application of fermentable substrates could work with bio-P sludge depends on the presence of the required anaerobic microorganisms able to transform those substrates into VFAs ready to be used by PAOs. When direct application is not feasible, as in the case of methanol, a syntrophic consortium strategy could be required.

\subsection{Methanol-driven EBPR using a syntrophic consortium}

The purpose of this consortium was to obtain a methanol-based EBPR sludge with methanoldegrading acetogens converting methanol to VFAs, which in turn would be used by PAOs as carbon source for biological removal purposes. This syntrophic consortium was obtained in two steps. In a first step, an anaerobic sludge was subjected to conditions so that anaerobic methanol degradation via acetogenesis was favored against methanogenesis. Then, in a second step, this acetogenic-enriched sludge system was bioaugmented with PAO-enriched sludge so that PAOs live off the acetogenesis products.

\subsubsection{Selection of methanol-degrading acetogens}

The initial consortium from a conventional anaerobic WWTP digester contained the classical anaerobic digestion microfauna (fermentative, acidogens, acetogens, methanogens...). Among these, we wanted to enrich our sludge with methanol-consuming acetogens in order to produce VFAs. Methanol-degrading acetogenesis produces $\mathrm{H}_{2}-\mathrm{CO}_{2}$ or acetate (Paulo et al., 2003). We aimed at PAOs growing on this acetate produced. Conversely, several species of methanogens and acetogens are able to utilize methanol as carbon and energy source for growth without a previous step of acetogenesis (Jarrel and Kalmokoff, 1988), which is not desired in this study. In our case, methanogenic activity needs to be suppressed for three reasons: i) methanogens could compete for methanol with acetogens, ii) methanogens could 
compete for acetate with PAOs and iii) methanogens could use hydrogen as electron donor. This would indirectly decrease acetate formation from methanol since conversion of methanol to $\mathrm{H}_{2} / \mathrm{CO}_{2}$ is very sensitive to the $\mathrm{H}_{2}$ partial pressure (Conrad et al., 1986).

If methanol is added as carbon source, substrate competition between methanogens and acetogens during the degradation of methanol will occur and several factors such as inorganic carbon, cobalt, methanol concentration or undissociated VFAs concentration can play a key role in this competition. The work of Florencio et al. (1993a,b and 1995) set the guidelines to understand this competition. In short, acetogenesis is expected to predominate if the methanol concentration is high (>1000 $\left.\mathrm{mg} \cdot \mathrm{L}^{-1}\right)$, exogenous inorganic carbon is supplied, cobalt (at least $0.2 \mathrm{mg} \cdot \mathrm{L}^{-1}$ ) is available and methanogens are inhibited. This inhibition can be caused either by a high amount of undissociated VFAs, by the presence of inhibitors like bromoethanesulfonic acid (BESA) or by specific toxics of methanogens such as dichloromethane and chloroform. Temperature is also an important feature (Kotsyurbenko et al., 1996, 2001; Speece, 1996); while acetogens and methanogens are equally active at a medium temperature range (around $25^{\circ} \mathrm{C}$ ), acetogenic activity dominates at lower temperatures $\left(<15^{\circ} \mathrm{C}\right)$ and methanogens are more active at higher temperatures $\left(>30^{\circ} \mathrm{C}\right)$. Kalle et al. (1984) observed the distribution of VFAs in a biogas digester at different temperatures. At $25^{\circ} \mathrm{C}$ it contained $87-88 \%$ VFAs, in comparison to $38 \%$ observed in the digester operating at $35^{\circ} \mathrm{C}$. In view of a posterior symbiotic coexistence with PAOs, temperatures around $20-25^{\circ} \mathrm{C}$ can be also beneficial to avoid the presence of GAOs, which are favored at high temperatures (Lopez-Vazquez et al., 2009).

Finally, oxygen was also a key parameter in this selection process, since an aerobic phase was required for PAOs to grow. The fact that oxygen is required for EBPR activity can be also helpful when suppressing methanogenic activity. Despite acetogens were considered strict anaerobes, it has been proved that they can grow under oxygen presence and are even capable 
to consume small amounts of oxygen (Karnholdz et al., 2002). On the other hand, Ferry (1993) or Kato et al. (1997) stated that despite methanogenic activity ceases in presence of oxygen, methanogens can be fairly tolerant to oxygen exposure. In any case, experimental reports suggest that acetogens are more resistant to oxygen than methanogens and hence, the aerobic phase may be more detrimental to the latter.

Then, SBR-C was inoculated with anaerobic sludge under configuration C1 (Table I). The average biomass concentration during this selection phase was $4770 \mathrm{mg} \mathrm{VSS} \cdot \mathrm{L}^{-1}$ (5930 mg TSS $\left.\cdot \mathrm{L}^{-1}\right)$. High temperature $\left(35^{\circ} \mathrm{C}\right)$ was initially chosen to favor complete anaerobic methanol degradation. Figure 3 shows the experimental methanol profiles during this enrichment period. During the first 8 days, the system was working under $\mathrm{C} 1$ conditions to favor anaerobic methanol degradation. Next, at day 8 , the last 30 minutes of anaerobic phase were changed to aerobic conditions (configuration C2). Methanol degradation decreased with this configuration, suggesting that partial inhibition took place when oxygen was introduced in the system. However, configuration C2 was maintained and, at day 22, the results indicated that the biomass was adapted to anaerobic methanol consumption without being inhibited by the final aeration phase of 30 minutes. Then, configuration C3 was applied extending the cycle length to 8 hours with longer aeration times ( 2 hours) and using lower temperature $\left(25^{\circ} \mathrm{C}\right)$. These changes resulted in slower substrate uptake and consequently, the initial methanol concentration was lowered to $150 \mathrm{mg} \cdot \mathrm{L}^{-1}$ so that all the COD was consumed during the anaerobic phase.

During the anaerobic phase of all this period, base was dosed to maintain $\mathrm{pH}$ at the desired setpoint. According to equation 3 (Heijthuijsen and Hansen, 1986), it was a clear indication of VFAs production from methanol, because 0.25 mols of protons are produced for each mol of methanol consumed for acetogenesis.

$$
4 \mathrm{CH}_{3} \mathrm{OH}+2 \mathrm{HCO}_{3}^{-} \rightarrow 3 \mathrm{CH}_{3} \mathrm{COO}^{-}+\mathrm{H}^{+}+4 \mathrm{H}_{2} \mathrm{O}
$$


Moreover, it should be noted that, as indicated by Florencio et al. (1995), around $10 \%$ of the initial methanol is used for growth purposes in the acetogenic metabolism and thus it could be assumed that at least $10 \%$ of the initial methanol would be lost for growth purposes and not converted to acetate.

Several experiments were conducted to corroborate anaerobic production of acetic acid from methanol. A pulse of $600 \mathrm{mg} \cdot \mathrm{L}^{-1}$ of methanol was added to anaerobic sludge that had been daily aerated during 30 min (Figure 4). Around $10 \%$ in weight basis of acetic acid production was observed after 24 hours. This production was lower than the theoretical one if methanogens were totally inhibited (i.e. equation 3) indicating that either methanogenesis had not been totally inhibited or that some other methanol-consuming microorganisms were present

The extent of methanogenesis was assessed with another batch experiment where the acetic acid uptake rate obtained with a periodically aerated anaerobic sludge was compared to that obtained with an anaerobic sludge never exposed to aerobic conditions. Acetic acid uptake rate was evaluated for both experiments obtaining $30.06 \mathrm{mg} \cdot \mathrm{L}^{-1} \cdot \mathrm{h}^{-1}$ for the non-aerated sludge and $21.24 \mathrm{mg} \cdot \mathrm{L}^{-1} \cdot \mathrm{h}^{-1}$ for the periodically aerated sludge. These values indicate that i) part of the methanogenic activity was reduced and ii) part of the acetic acid from anaerobic methanol degradation observed during the consortium build-up was likely converted to $\mathrm{CO}_{2}$ and methane. Nevertheless, it was expected a progressive decrease of methanogenic activity after PAOs bioaugmentation due to its competition for acetate under anaerobic conditions.

\section{$\underline{\text { 3.2.2 PAOs bioaugmentation, simultaneous } \mathrm{P} \text { and methanol removal }}$}

Negligible P-release or uptake was observed in SBR-C before PAO bioaugmentation, despite the anaerobic/aerobic phases. A significant amount of PAOs or GAOs was not expected in the inoculum sludge from the WWTP anaerobic digester. PAOs and GAOs can store VFAs under 
anaerobic conditions, but they need an electron acceptor (oxygen, nitrate or nitrite) to grow, and these alternate conditions are not found in an anaerobic digester.

PAOs were bioaugmented into SBR-C to promote EBPR after 25 days of methanol-degrading acetogens growth under sequential anaerobic-aerobic-settling cycles. This bioaugmentation was conducted with 4 liters of enriched-PAO sludge from SBR-B (conventional anaerobicaerobic configuration with propionic acid as carbon source). The initial biomass concentration in the bioaugmented system was $5290 \mathrm{mg} \mathrm{VSS} \cdot \mathrm{L}^{-1}\left(6135 \mathrm{mg} \mathrm{TSS} \cdot \mathrm{L}^{-1}\right.$, VSS/TSS $\left.=0.86\right)$. Table II reports the biomass composition of the enriched-PAO sludge (SBR-B) and the bioaugmented SBR-C. Figure 5 shows the experimental profiles of one cycle from the first three days. As observed, net-P removal (P-release and P-uptake) was achieved from the first day and was effectively maintained during the first three days with similar experimental profiles. In fact, $\mathrm{P}$ release rate increased up to $25 \%$ when comparing day 3 and day 1. Assuming that methanol is not directly consumed by propionic acid-fed PAOs (as previously determined in the direct replacement strategy), EBPR activity indicated that PAO were growing on the acetic acid generated by acetogens in the methanol degradation. Regarding the methanol consumption (Figure 6), it was observed that around $50 \mathrm{mg} / \mathrm{L}$ of methanol were consumed during the first days of operation, but this amount increased along the operation to $90 \mathrm{mg} / \mathrm{L}$ on day 17 . To reduce the methanol remaining at the end of the aerobic phase, the initial amount was reduced to $90 \mathrm{mg} / \mathrm{L}$, achieving a concentration around $20 \mathrm{mg} / \mathrm{L}$ at the end of the anaerobic phase.

The system was run during more than 30 days and several cycles were monitored during this period. As can be observed, net-P removal was achieved most of the time, indicating that the syntrophic consortium was able to use methanol as sole carbon source for EBPR purposes. The biomass concentration decreased at the end of this period to $3784 \mathrm{mg} \mathrm{VSS} \cdot \mathrm{L}^{-1}(4540 \mathrm{mg}$ TSS $\mathrm{L}^{-1}$ ) but maintaining a VSS/TSS ratio of 0.83 . The phosphorus content of the biomass 
was estimated with equation 2 and a high value around $0.06 \mathrm{~g} \mathrm{P} \cdot \mathrm{g}^{-1} \mathrm{VSS}$ was obtained, supporting the observed EBPR activity.

However, both the average of the experimental $\mathrm{P} / \mathrm{C}_{\mathrm{MET}}$ ratio $\left(\mathrm{mol} \mathrm{P} \cdot \mathrm{mol}^{-1} \mathrm{C}-\mathrm{methanol}\right)$ and the FISH measurements indicated a possible proliferation of GAOs under the operating conditions. Table II shows that both DF1 and DF2 almost disappeared from the system, while GAOMIX-binding cells increased up to 5.4\%. The presence of GAOMIX type GAOs with acetate as carbon source has been extensively reported (Oehmen et al., 2007). The increase of GAOMIX linked to the decrease of DF1 and DF2 is consistent with the hypothesis of methanol degradation mostly to acetate rather than propionate. The experimental $\mathrm{P} / \mathrm{C}_{\mathrm{MET}}$ ratio was $0.54 \pm 0.11(n=9)$, during the first 15 days and it decreased up to $0.38 \pm 0.08(n=8)$ during the last period.

The theoretical maximum $\mathrm{P} / \mathrm{C}_{\mathrm{MET}}$ ratio should be around 0.75 assuming that $\mathrm{i}$ ) the initial methanol was all converted to acetic acid (for every 4 mole of methanol 3 mole of acetic were formed) and ii) the theoretical $\mathrm{P} / \mathrm{C}_{\mathrm{ACET}}$ ratio was 0.5 . Three different plausible hypotheses can explain the fact that the experimental P/C ratio was lower than the theoretical one: i) part of the methanol was used for growth purposes, ii) part of the methanol was anaerobically degraded in a different pathway than desired (e.g. acidogenic butyrate formation, Kerby et al., 1983, Heijthuijsen and Hansen, 1986, formaldehyde or methane production Gonzalez-Gil et al., 1999; Florencio et al., 1993a) or iii) part of the acetate was used by other microorganisms than PAOs (e.g. GAOs). The first hypothesis would explain only a $10 \%$ decrease in the P/C ratio, as $10 \%$ is the approximate amount of methanol devoted to growth and not transformed to acetate (Florencio et al., 1995).

Regarding the second hypothesis, no other intermediate apart from acetic acid (e.g. propionic acid or formaldehyde) was detected in any chromatographic analysis performed in the anaerobic samples. Nevertheless, a batch experiment with an enriched PAO-sludge was 
performed to exclude the possible use of formaldehyde as intermediate of the observed methanol-driven EBPR. It was tested whether PAOs could uptake formaldehyde and, as expected, the results indicate that it was toxic or inhibitory (Figure 7). Formaldehyde concentration slightly decreased in this experiment, but it was linked to a high P-release, even under aerobic conditions. No P-uptake was observed and hence formaldehyde was likely more a toxic or inhibitor of PAOs rather than a suitable carbon source.

On the other hand, the hypothesis of acetate utilization by GAOs is confirmed by FISH results. Although EBPR activity was maintained for one month, the PAOs percentage decreased from $19 \%$ to $11 \%$, while the total amount of GAOs (sum of DF1, DF2 and GAOMIX) simultaneously increased from 3.4 to $5.6 \%$. Considering these values, the percentage of PAOs with respect the sum of GAOs and PAOs decreased from 85 to $66 \%$. The $\mathrm{P} / \mathrm{C}$ ratio calculated at the end of the period considering the initial $\mathrm{P} / \mathrm{C}$ ratio of 0.54 and the change in these percentages is 0.42 , which fairly agrees with the experimental ratio of $0.38 \pm 0.08$. This result would exclude an important contribution of the second hypothesis. Nevertheless, the possible presence of other GAO-phenotype microorganisms not labeled with GAOMIX, DF1MIX or DF2MIX probes cannot be ruled out. In this sense, the identification and elucidation of the role of other microorganisms present in this novel syntrophic microbial community seems to be an interesting further research work for the whole understanding of this novel strategy for P-removal. Finally, despite that the feasibility of EBPR with methanol using this syntrophic consortium of methanol-degraders and PAOs is clearly shown in this work, future research in this field should aim at avoiding the long-term presence of GAOs or different anaerobic pathways.

\section{CONCLUSIONS}

Methanol-driven EBPR (P-removal using methanol as sole carbon source) was obtained using a syntrophic consortium between methanol-degrading acetogens and PAOs. The first would 
be in charge of converting methanol to byproducts, which could be used by PAOs as carbon source for biological P-removal. This syntrophic consortium was obtained using a two-step procedure: an anaerobic sludge was subjected to conditions favoring methanol degradation via acetogenesis and then it was bioaugmented with PAO-enriched sludge.

Conversely, a previous strategy with direct replacement of propionic acid by methanol in a conventional anaerobic-aerobic configuration demonstrated that only enriched PAO biomass was unable to survive using methanol as sole carbon source.

\section{ACKNOWLEDGMENTS}

Carlota Tayà acknowledges the support of Universitat Autònoma de Barcelona with a predoctoral grant. Javier Guerrero is grateful for the grant received from the Spanish government (FPU AP2009-1632). Gianni Vanneste acknowledges the Erasmus grant received to visit UAB. This work was supported by the Spanish Ministerio de Ciencia y Tecnología (CTM2010-20384). The authors are members of the GENOCOV research group (Grup de Recerca Consolidat de la Generalitat de Catalunya, 2009 SGR 815).

\section{REFERENCES}

Amann RI, Ludwig W, Schleifer KH. 1995. Phylogenetic identification and in situ detection of individual microbial cells without cultivation. Microbiol Rev 59(1):143-169.

Brdjanovic D, Hooijmans CM, van Loosdrecht MCM, Alaerts GJ, Heijnen JJ. 1996. The dynamic effects of potassium limitation on biological phosphorus removal. Water Res 30(10):303-313. 
Cho E, Molof AH. 2004. Effect of sequentially combining methanol and acetic acid on the performance of biological nitrogen and phosphorus removal. J Environ Manag 73(3):183187.

Conrad R, Schink B, Phelps TJ. 1986. Thermodynamics of H2-consuming and H2-producing metabolic reactions in diverse methanogenic environments under in situ conditions. FEMS Microbiol Ecol 38:353-360.

Ferry JG. 1993. Methanogenesis: ecology, physiology, biochemistry \& genetics. Ed. Chapman and Hall, New York, USA.

Daims H, Brühl A, Amann R, Schleifer KH, Wagner M. 1999. The domain-specific probe EUB338 is insufficient for the detection of all bacteria: Development and evaluation of a more comprehensive probe set. Syst Appl Microbiol 22(3):434-444.

Florencio L, Field JA, Lettinga G. 1995. Substrate competition between methanogens and acetogens during the degradation of methanol in UASB reactors. Water Res 29(3):915-922. Florencio L, Jenicek P, Field JA, Lettinga G. 1993a. Effect of cobalt on anaerobic degradation of methanol. J Ferment Bioeng 75:368-374.

Florencio L, Nozhevnikova A, van Langerak A, Stams AJM, Field JA, Lettinga G. 1993b. Acidophilic degradation of methanol by a methanogenic enrichment culture. FEMS Microbiol Lett 109:1-6.

Gonzalez-Gil G, Kleerebezem R, Lettinga G. 1999. Effects of nickel and cobalt on kinetics of methanol conversion by methanogenic sludge as assessed by on-line $\mathrm{CH} 4$ monitoring. Appl Environ Microbiol. 65:1789-1793.

Guerrero J, Tayà C, Guisasola A, Baeza JA. 2012. Glycerol as a sole carbon source for enhanced biological phosphorus removal. Water Res 46(9):2983-2991.

Guisasola A, Qurie M, Vargas MM, Casas C, Baeza JA. 2009. Failure of an enriched nitriteDPAO population to use nitrate as an electron aceptor. Process Biochem 44(7):689-695. 
Heijthuijsen JHFG, Hansen TA. 1986. Interspecies Hydrogen transfer in co-cultures of methanolutilizing acidogens and sulfate-reducing or methanogenic bacteria. FEMS Microbiol. Lett 38:57-64.

Isaacs SH, Henze M. 1995. Controlled carbon source addition to an alternating nitrificationdenitrification wastewater treatment process including biological P removal. Water Res 29(1):77-89.

Jarrel KF, Kalmokoff ML. 1988. Nutritional requirements of the methanogenic archaebacteria. Can J Microbiol. 34:557-576.

Jeon CO, Park JM. 2000. Enhanced biological phosphorus removal in a sequencing batch reactor supplied with glucose as a sole carbon source. Water Res 34(7):2160-2170.

Jubany I, Lafuente J, Carrera J, Baeza JA. 2009. Automated thresholding method (ATM) for biomass fraction determination using FISH and confocal microscopy. J Chem Technol Biot $84: 1140-1145$.

Kalle GP, Menon KKG. 1984. Inhibition of methanogenesis and its reversal during biogas formation from cattle manure. J Biosci 3:315-324.

Kato MT, Field JA, Lettinga G. 1997. Anaerobe tolerance to oxygen and the potentials of anaerobic and aerobic cocultures for wastewater treatment. Braz J Chem Eng 14:4.

Kerby R, Niemczura W, Zeikus JG. 1983. Single-carbon catabolism in acetogens: analysis of carbon flow in Acetobacterium woodii and Butyribacterium methylotrophicum by fermentation and ${ }^{13} \mathrm{C}$ nuclear magnetic resonance measurement. J Bacteriol 155:1208-1218. Kotsyurbenko OR, Glagolev MV, Nozhevnikova AN, Conrad R. 2001. Competition between homoacetogenic bacteria and methanogenic archaea for hydrogen at low temperature. FEMS Microbiol Ecol 38:153-159. 
Kotsyurbenko OR, Nozhevnikova AN, Soloviova TI, Zavarzin GA. 1996. Methanogenesis at low temperatures by microflora of tundra wetland soil. Anthonie van Leewuenhoek 69(1):7586.

Lopez C, Pons MN, Morgenroth E. 2006. Endogenous processes during long-term starvation in activated sludge performing enhanced biological phosphorus removal. Water Res 40(8):1519-1530.

Lopez-Vazquez C, Oehmen A, Hoojimans CM, Brdjanovic D, Gijzen HJ, Yuan Z, van Loosdrecht MCM. 2009. Modeling the PAO-GAO competition: Effects of carbon source, pH and temperature. Water Res 43(2):450-462.

Louziero N, Mavinic DS, OldhamWK, Meisen A, Gardner IS. 2002. Methanol-induced biological nutrient removal kinetics in a full-scale sequencing batch reactor. Water Res 36(11):2721-2732.

Lu H, Keller J, Yuan Z. 2007. Endogenous metabolism of Candidatus Accumulibacter phosphatis under various starvation conditions. Water Res. 41(20):4646-4656.

Marcelino M, Guisasola A, Baeza JA. 2009. Experimental assessment and modelling of the proton production linked to phosphorus release and uptake in EBPR systems. Water Res 43(9):2431-2440.

Oehmen A, Lemos PC, Carvalho G, Yuan Z, Keller J, Blackall LL, Reis MAM. 2007. Advances in enhanced biological phosphorus removal: from micro to macro scale. Water Res 41(11):2271-2300.

Paulo PL, Stams AJM, Field JA, Dijkema C, van Lier JB, Lettinga G. 2003. Pathways of methanol conversion in a thermophilic anaerobic $\left(55^{\circ} \mathrm{C}\right)$ sludge consortium. Appl Mirobiol. Biotechnol 63:301-314. 
Pijuan M, Saunders AM, Guisasola A, Baeza JA., Casas C, Blackall LL. 2004. Enhanced biological phosphorus removal in a sequencing batch reactor using propionic acid as the sole carbon source. Biotechnol Bioeng, 85(1):56-67.

Pijuan M, Casas C, Baeza JA. 2009. Polyhydroxyalkanoate synthesis using different carbon sources by two enhanced biological phosphorus removal microbial communities. Process Biochem. 44(1): 97-105.

Puig S, Coma M, Monclús H, van Loosdrecht MCM, Colprim J, Balaguer MD. 2008.

Selection between alcohols and volatile fatty acids as external carbon sources for EBPR. Water Res 42(3):557-566.

Purtschert I, Siegrist H, Gujer W. 1996. Enhanced denitrification with methanol at WWTP Zürich-Werdhölzli. Water Sci Technol 33(12):117-126.

Randall AA, Benefield LD, Hill WE. 1997. Induction of phosphorus removal in an enhanced biological phosphorus removal bacterial population. Water Res 31(11):2869-2877.

Speece RE. 1996. Anaerobic Biotechnology for Industrial Wastewaters. Archae Press, New York, USA.

Tong JA, Chen YG. 2007. Enhanced biological phosphorus removal driven by short-chain fatty acids produced from waste activated sludge alkaline fermentation. Environ Sci Technol 41(20):7126-7130.

Yilmaz G, Lemaire R, Keller J, Yuan Z. 2007. Effectiveness of an alternating aerobic, anoxic/anaerobic strategy for maintaining biomass activity of BNR sludge during long-term starvation. Water Res 41(12):2590-2598.

Yuan Q, Sparling R, Lagasse P, Lee YM, Taniguchi D, Oleszkiewicz JA. 2010. Enhancing biological phosphorus removal with glycerol. Water Sci Technol 61(7):1837-1843. 
Zeng RJ, Yuan Z, Keller J. 2003. Model-based analysis of anaerobic acetate uptake by a mixed culture of polyphosphate-accumulating and glycogen-accumulating organisms. Biotechnol Bioeng 83(3):293-302. 
Table I Summary of the configurations used in SBR-C for the obtainment of a syntrophic consortium of methanol-degrading acetogens and PAOs

\begin{tabular}{cccccc}
\hline Configuration & $\begin{array}{c}\text { Cycle configuration (h) } \\
\text { (Anaerobic-aerobic-settling) }\end{array}$ & HRT (h) & $\mathbf{T}\left({ }^{\mathbf{o}} \mathbf{C}\right)$ & Base used & $\begin{array}{c}\text { Feed Cobalt } \\
\left(\mathbf{m g} \cdot \mathbf{L}^{\mathbf{- 1}}\right)\end{array}$ \\
\hline $\mathrm{C} 1$ & $6(4.5+0+1.5)$ & 19.5 & 35 & $\mathrm{NaHCO}_{3}$ & 0.2 \\
\hline $\mathrm{C} 2$ & $6(4+0.5+1.5)$ & 19.5 & 35 & $\mathrm{NaHCO}_{3}$ & 0.2 \\
\hline $\mathrm{C} 3$ & $8(5+2+1)$ & 26 & 25 & $\mathrm{NaHCO}_{3}$ & 0.2 \\
\hline
\end{tabular}

Table II Summary of different FISH measurements for the syntrophic consortium study

\begin{tabular}{cccc}
\hline & $\begin{array}{c}\text { SBR-B } \\
\text { (PAO-enriched sludge) }\end{array}$ & $\begin{array}{c}\text { SBR-C } \\
\text { (start bioaugmentation) }\end{array}$ & $\begin{array}{c}\text { SBR-C } \\
\text { (end bioaugmentation) }\end{array}$ \\
\hline GAO, DF1 & $1.9 \pm 0.3$ & $0.6 \pm 0.1$ & $0.06 \pm 0.01$ \\
\hline GAO, DF2 & $5.1 \pm 1.0$ & $1.6 \pm 0.3$ & $0.17 \pm 0.03$ \\
\hline GAO, GAOMIX & $3.8 \pm 1.0$ & $1.2 \pm 0.3$ & $5.4 \pm 2.1$ \\
\hline PAOMIX & $61 \pm 6$ & $19 \pm 2$ & $11 \pm 3$ \\
\hline
\end{tabular}



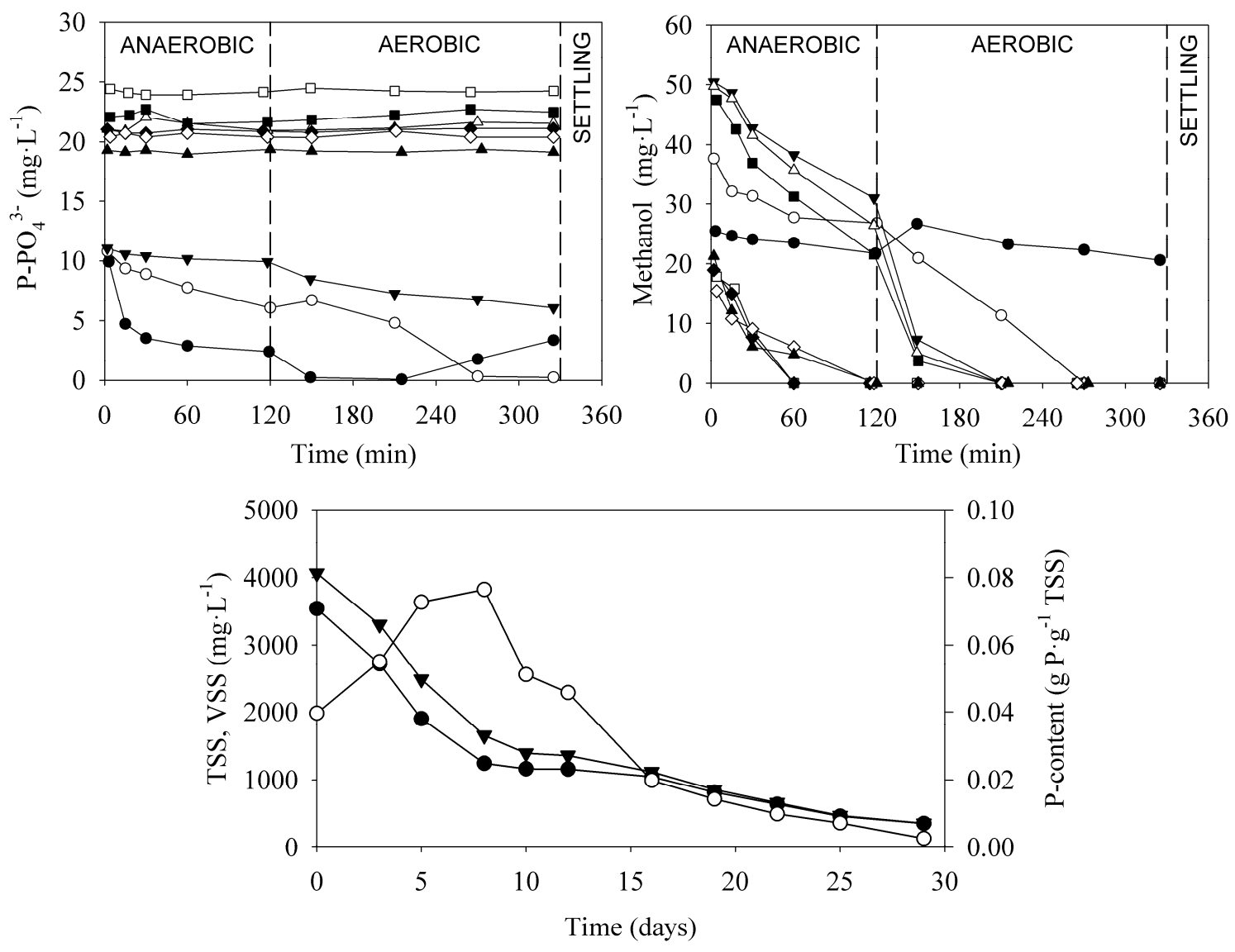

Figure 1 Experimental profiles obtained during the direct replacement experiment. Up: Phosphorus and methanol profiles for 9 cycles of this period ( $\bigcirc$ day $1, \bigcirc$ day $3, \boldsymbol{\nabla}$ day $5, \triangle$ day $8, \square$ day $10, \square$ day $12, \diamond$ day $16, \diamond$ day 19 and $\boldsymbol{\Delta}$ day 25$)$. Down: $\bullet$ VSS, $\boldsymbol{\nabla}$ TSS and $\bigcirc$ P-content profiles. 


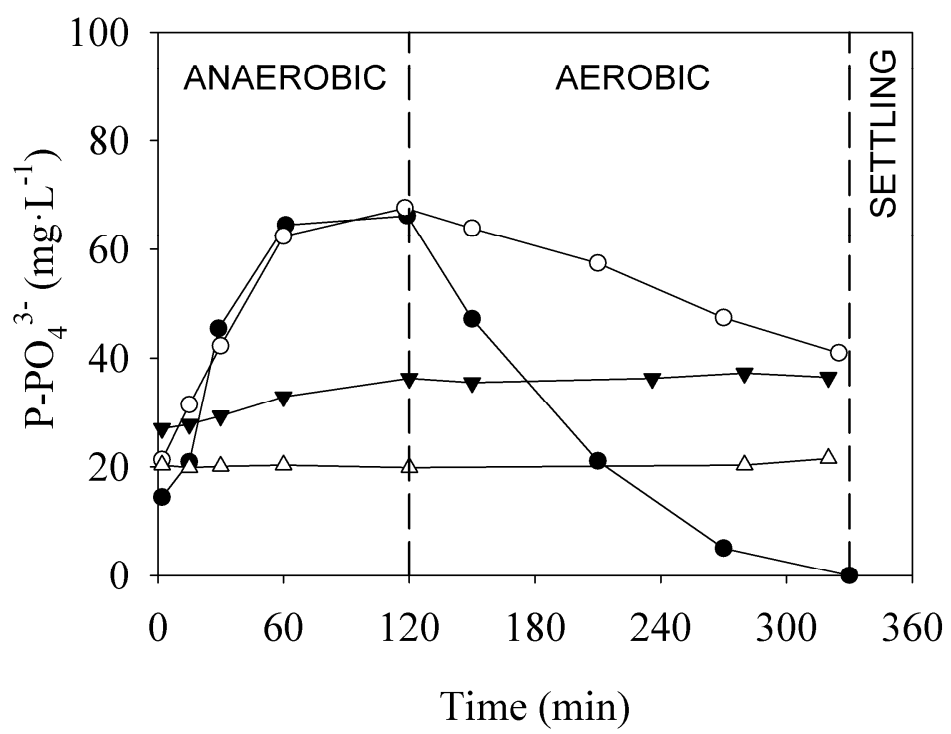

Figure 2 Batch experiments conducted during the direct replacement experiment using propionic acid as carbon source to assess PAO activity ( $\bigcirc$ day $1, \bigcirc$ day $12, \boldsymbol{\nabla}$ day 22 and $\triangle$ day 33). 

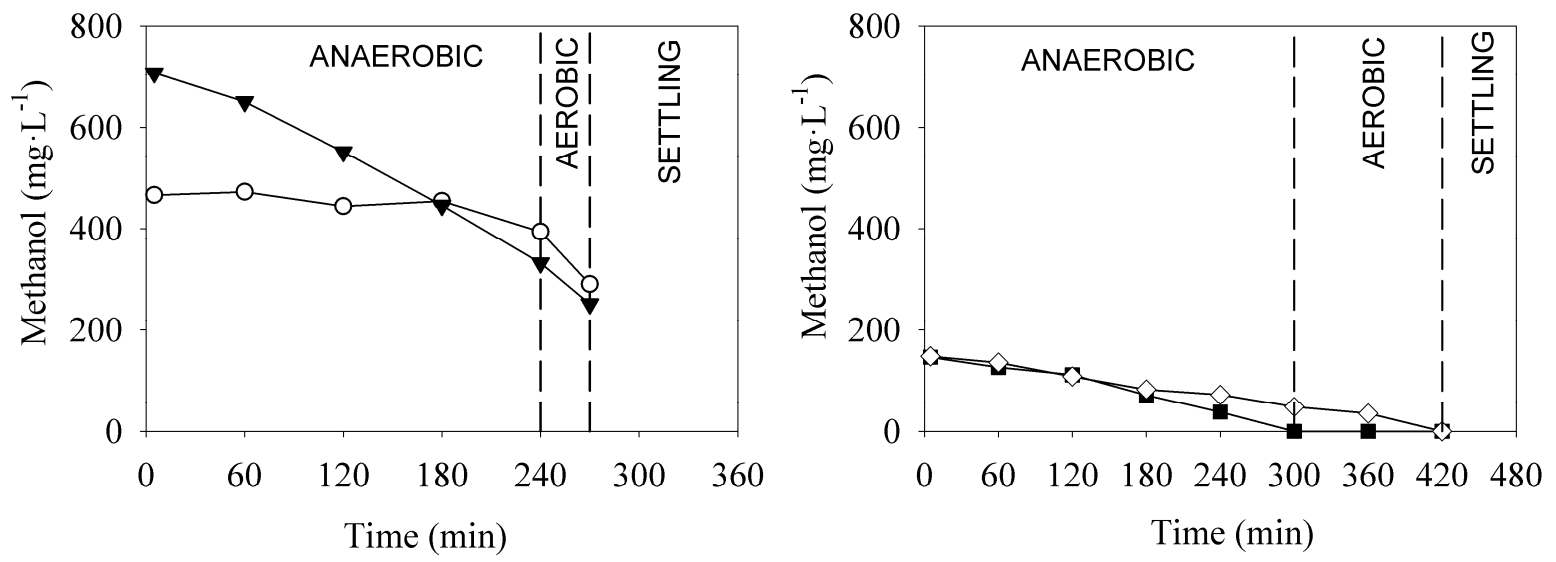

Figure 3 Different cycles from the acetogenic selection period with methanol as sole carbon source. Left: Anaerobic-aerobic-settling period C2 ( $\bigcirc$ day 9, $\nabla$ day 22). Right: Anaerobicaerobic-settling period C3 ( $\diamond$ day 24 and $\mathbf{\square}$ day 26$)$. 


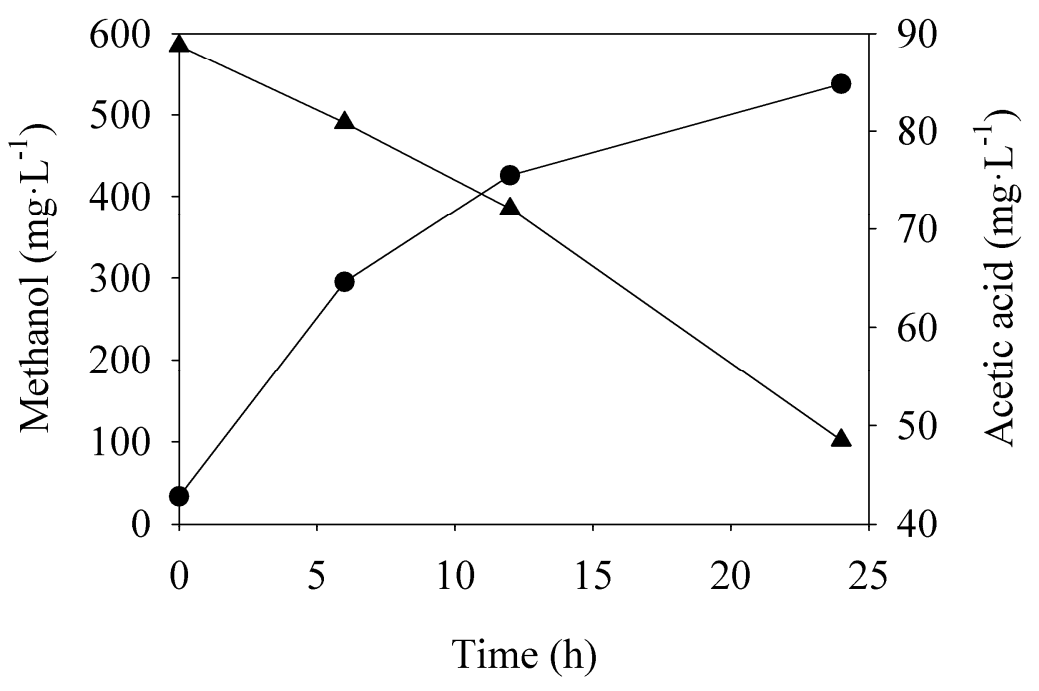

Figure 4 Batch experiment with addition of $600 \mathrm{mg} \cdot \mathrm{L}^{-1}$ of methanol to anaerobic sludge periodically aerated. Acetic acid and $\boldsymbol{\Delta}$ methanol. 


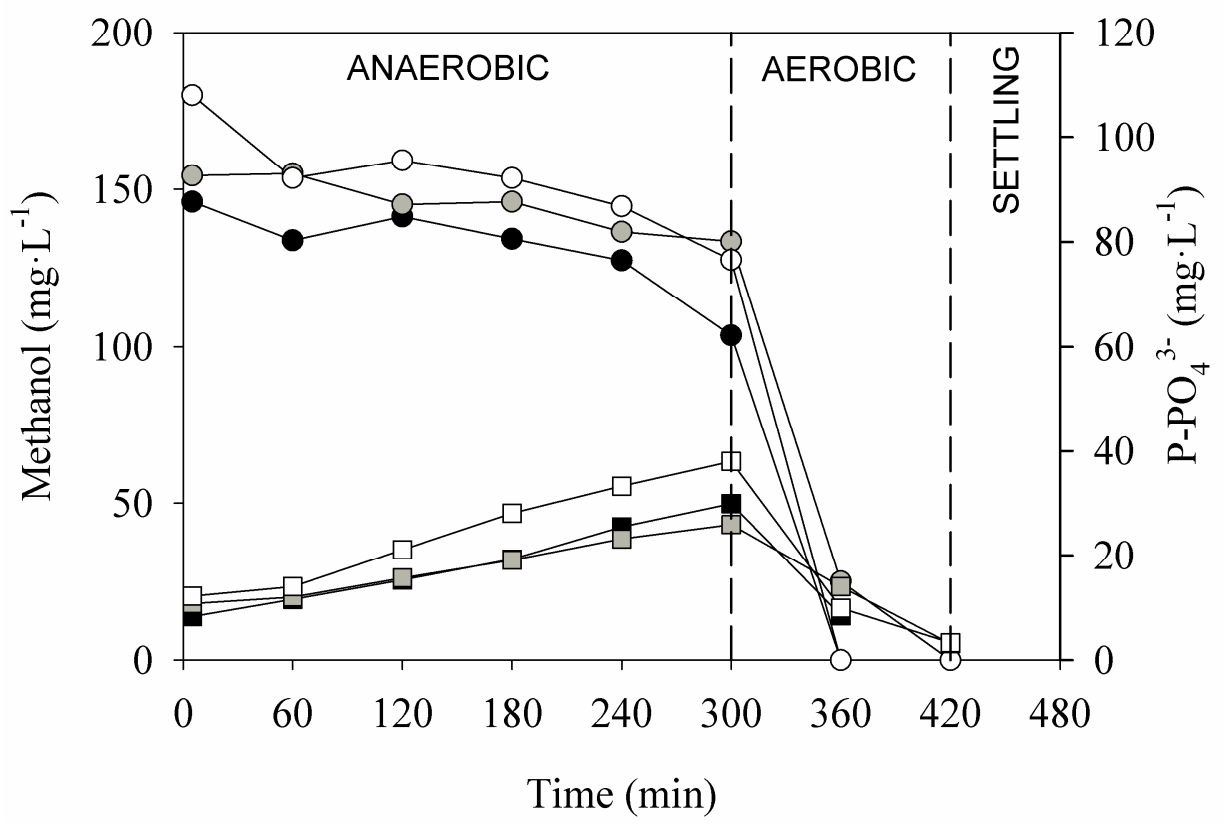

Figure 5 Experimental P ( $\square)$ and methanol (०) profiles of the first cycles with the acetogenicPAO consortium period (black: day 1, grey: day 2, white: day 3) 

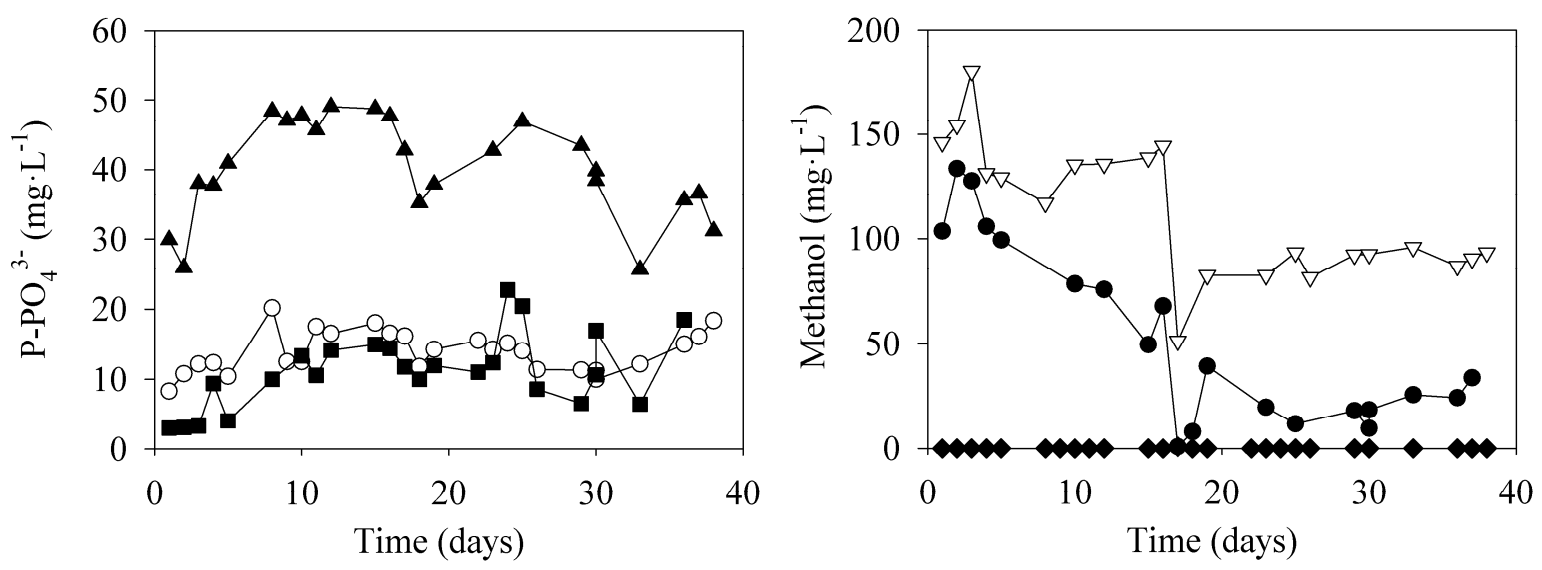

Figure 6 Experimental $\mathrm{P}$ and methanol profiles during the syntrophic acetogenic-PAO consortium period. Left) $\mathrm{P}$ start of cycle $(\mathrm{O}), \mathrm{P}$ end of anaerobic phase $(\mathbf{\Delta})$ and $\mathrm{P}$ end of aerobic phase ( $\mathbf{\square})$. Right) methanol start of cycle $(\nabla)$, methanol end of anaerobic phase $(\boldsymbol{O})$ and methanol end of aerobic phase $(\diamond)$. 


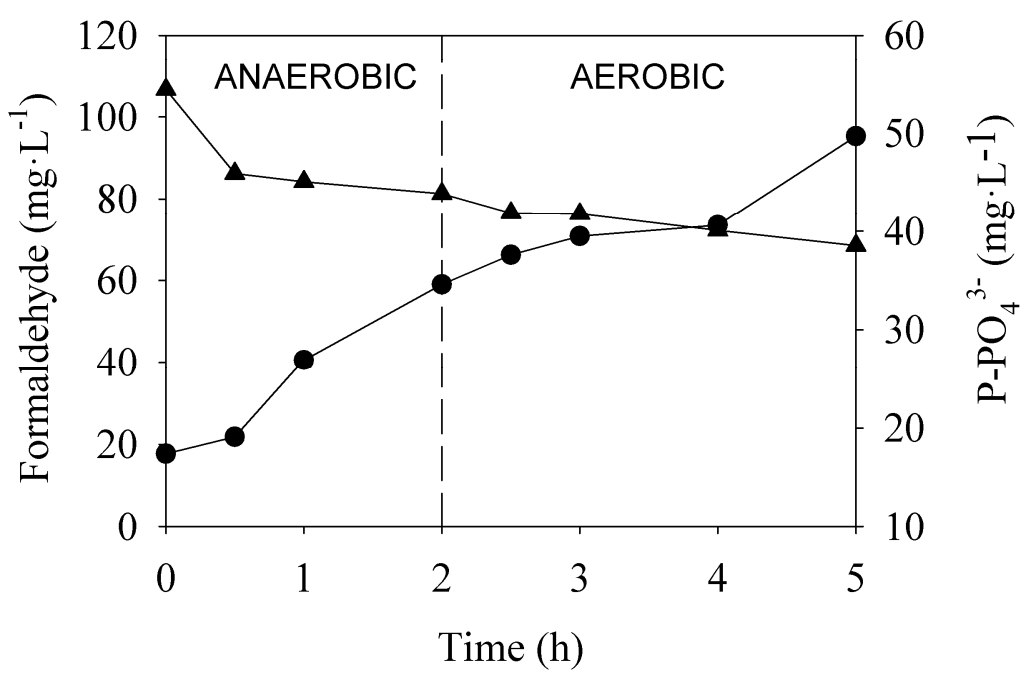

Figure 7 Experimental $\mathrm{P}$ and formaldehyde profiles obtained in an anaerobic/aerobic batch experiment with a PAO-enriched sludge. $\boldsymbol{\Delta}$ Formaldehyde and $\boldsymbol{\bullet}$ phosphate. 